\title{
Designing Assessments for Blended Learning Scenarios
}

\author{
Mary Webb*, Stylianos Hatzipanagos**, Jonathan San Diego*, Ehsan Khan* and \\ Mateusz Goral***. \\ *King's College London, UK, \\ **University of West London, \\ ***City University \\ mary.webb@kcl.ac.uk, s.hatzipanagos@uwl.ac.uk jonathan.p.san_diego@kcl.ac.uk, \\ eu.khan@kcl.ac.uk, matt.goral@city.ac.uk
}

Keywords: assessment design, online learning, blended learning, assessment

\section{Introduction}

This article examines the design process required for developing assessments within blended learning scenarios. Furthermore, we examine how practitioners in higher education can be supported to develop their understanding of assessment and how to design assessments into their teaching. We focus specifically on blended learning scenarios where the expectation is that learning will be achieved through a mix of face-to-face and online interaction. However, as blended learning is a relatively broad term that may incorporate situations that are predominantly face-to-face or predominantly online, many of the principles will also apply across a broad range of learning situations. The article draws on findings from analysing the needs of students and lecturers and common issues relating to access to online educational resources across a partnership of Indian and European universities involved in the EQUAL Project [1]. The project addressed a range of subject areas to develop design processes and implement teaching and learning resources and activities for use in various blended learning scenarios [2]. One benefit of drawing on this project, is that the considerations in this study, ranged across needs of students from different backgrounds and contexts as well as institutions with different infrastructure provision. Therefore, our analysis has fairly broad considerations and applications.

In this article, we first outline the terminology and present our analysis of important perspectives on assessment, in relation to the needs of blended learning scenarios. We then examine considerations regarding who or what is the assessor: the teacher, the student, their peers or technology. We provide a brief overview of possible influences of changing assessment practices in higher education. Next, we outline the assessment design considerations identified as being essential for blended learning scenarios by examining the potential use of the revised Bloom's taxonomy [3] incorporated into a decision support tool to assist teachers in thinking about designing assessments [2]. Finally, we discuss teachers' professional development needs and challenges in relation to designing assessments in situations where electronic and/or online opportunities are increasing. 


\section{Terminology of assessment}

Although, formative and summative assessment are commonly used terms in higher education, our experience suggests that these and related terms have varying meanings in different contexts and confusion remains. Therefore, we will first define the terms we use and outline the issues that may inhibit effective debate in this area. The term assessment itself is relatively unambiguous in that it refers to the checking of someone's knowledge, understanding, skills or capabilities. However, this same term is applied both to the process of checking and to the outcome of this process. Furthermore, in some educational circles, the term evaluation is used in place of assessment. In this article we have used evaluation as a broader term relating to understanding the overall successes and failures of a course or programme rather than for assessing students.

Four perspectives on assessment have been identified as shown in the model presented in Table 1 [4]. This model distinguishes between a focus on the assessment process and on the results of the assessment. Furthermore, the model refers to "Assessment FOR learning" and "Assessment OF learning" [5]. These terms have been used in various educational circles, in place of formative assessment and summative assessment respectively, in order to emphasise the purpose of assessment and its relationship with learning.

Table 1. Four ways to think about assessment [4]

\begin{tabular}{|l|c|c|}
\hline $\begin{array}{l}\text { Assessment FOR learn- } \\
\text { ing }\end{array}$ & $\begin{array}{c}\text { PROCESS Focus } \\
\text { Feedback discussions } \\
\text { and information }\end{array}$ & $\begin{array}{c}\text { RESULTS Focus } \\
\text { Improvement decisions } 2\end{array}$ \\
\hline Assessment OF learning & $\begin{array}{c}\text { Perspective 3 } \\
\text { Degree of engagement } \\
\text { with/understanding of pro- } \\
\text { cess }\end{array}$ & $\begin{array}{c}\text { Perspective 4 } \\
\text { Value judgements }\end{array}$ \\
\hline
\end{tabular}

Referring to Table 1, Perspective 1 is about students learning from feedback discussions and information provided during an assessment process. Perspective 2, focuses on using results of assessment for adapting teaching and learning processes. The third perspective is about the extent to which students understand the assessment process and are able and willing to engage with it. This perspective reminds us that ensuring that our assessments are accurate reflections of students' achievements is by no means straightforward. The need to understand what will be assessed and how the assessments will be conducted becomes particularly significant when students are learning not only from the materials and teaching sessions that lecturers provide, but from a broad range of online opportunities not necessarily recommended by the lecturers, including for example MOOCs that have become a significant and controversial issue in higher education provision [see for example 6]. Perspectives 1, 2 and 3 are all key elements of formative assessment, which, by definition, supports students' learning and may be carried out by teachers, peers and/or students on themselves (self-assessment). Perspective 3 is important both for formative and summative assessment because, in order to generate 
valid assessment information, students need to understand the assessment process and engage with it. Perspective 4 is about making summative judgements for purposes of grading and accreditation. Clearly such judgements are important and necessary at transition points between elements of a programme of study and at the end.

Historically, evidence suggests that students fail to attend to feedback comments when given grades [7] and confusion regarding the utility and need for feedback remains today. For example, despite evidence of students preferring written feedback together with annotated assignments providing explicit detail, [8], studies have also shown that students do not always identify formative feedback as relevant [see for example 9]. Furthermore, students may not act on feedback owing to insufficient background knowledge or because the approach to feedback fails to take account of affective elements of learning [10]. Thus, feedback involves complex processes that may be facilitated by considering not only the nature of the material and assessment but also how to engage learners in the assessment and feedback processes.

\section{Assessors - teacher, self, peer, technology}

When designing assessments, in addition to considering the four perspectives outlined above, it is necessary to consider who/what is conducting and/or managing the assessment: student themselves, their peers, the teacher, technology in an automated system. Enabling students to self-assess is an important goal of education because self-assessment supports the potential for students to become independent learners and to learn efficiently from the wide range of opportunities available including online materials and activities. The ability to self-assess is also necessary for self-regulated learning (SRL). SRL, a psychological construct, refers to an active, constructive process in which students intentionally set learning goals and then plan, monitor and regulate their cognitive, behavioural, emotional and motivational processes in the service of those goals in order to achieve optimal learning (Pintrich 2004). The evidence suggests that one of the best ways of developing students' ability to self-assess is through peer assessment [see for example 11].

The process of peer assessment is most productive, as well as most acceptable to teachers and students, when it involves students assessing each other's work against specified criteria and providing feedback to each other, rather than trying to assign grades [12]. For peer assessment to be a formative assessment process the feedback needs to focus on what the student has achieved and what they should do to improve their work, together with some ideas about how to go about this improvement [11]. In formative feedback, dialogue forms the mechanism by which a learner monitors, identifies and then is able to 'bridge' the gap in the learning process [see for example 13, 14]. Therefore, effective peer assessment processes become dialogic processes between students. Just as with self-assessment, discussed above, a close relationship exists between good quality peer assessment processes and self-regulated learning. The peer interaction provides opportunities for co-regulation of learning or socially regulated learning [15] in which students support each other in regulating their learning. 
There is also a developing body of research in support of peer assessment as a summative assessment process. There is evidence that in some fields peer assessment is just as reliable as tutor assessment [16]. However, we believe that the reliability and acceptability of summative peer assessment depends on the particular discipline and the credibility and capability of the person giving feedback. Furthermore, peer assessment can meet resistance from both tutors and students [12] because in many institutions, the expectation is for teachers to teach and make judgements about students.

\section{Changes in assessment practices}

More generally, assessment practices in higher education have been changing and diversifying for some years. New approaches are emerging, based on developments in digital technologies, which are increasing the range of possibilities for assessments, including increasing opportunities for personalisation of assessments [17] and the capability for assessment to measure a broader range of knowledge and knowledge-inaction [18]. For example, students can be assessed through simulations, e-portfolios and interactive games [19] rather than end of term exams and essays. Evidence is compelling that the nature and form of assessment have a significant impact upon the student learning experience, approaches to learning, motivation, and retention rates [20].

In higher education, the nature of an institution often dictates how assessment practices have been developed. For example, open and distance learning environments have emphasized the necessity for formative assessment practices. Distance education in general has been proactive in formative assessment practices out of the need to find ways to provide systematic feedback and direction to students in the absence of the immediate contact and interaction that students have enjoyed with tutors in a campus setting [21]. However, in both types of environments, the impact of assessment on learning can be moderated by the use of appropriate assessment methods by teaching practitioners and practices have been supported/complemented by the use of computer assisted learning resources [22].

\section{$5 \quad$ Practical considerations in designing assessments}

Online assessments require good Internet connections and infrastructure issues in developing countries such as India may render online assessments unfeasible in the short term [2]. Therefore, consideration needs to be given to computer-based assessments that could be delivered off-line or within a local intranet. However, our expectations are that such technical problems may be resolved within a reasonable timescale and therefore institutions also need to look ahead to consider future options.

There are also a range of tools and systems that can be used to implement assessment designs. These may range from objective testing platforms (e.g. exam-builders, Questionmark, Moodle quiz, Learning Management Systems assessment tools, etc); e-portfolios tools (e.g. Mahara, Pebblepad, etc.); authoring tools (e.g. word-processors, HTML5, Storyline, etc.). 
Thus, assessment decisions may be influenced by or limited by infrastructure considerations and availability of technologies or knowledge about applicability of such technologies. With this wide range of opportunities becoming available, it is especially important for assessment designs to be considered as part of pedagogical designs.

\section{Assessment design within an overall pedagogical design}

For assessment practices to be effective in relation to the four perspectives outlined above their place in the overall pedagogical design needs to be clear. Our view, in line with Black's [14] five-stage model of assessment in pedagogy is that assessment considerations and actions need to be integrated in all aspects of pedagogy so that there is a match between the aims and the specific learning outcomes, the activities to support the aims and the methods of assessment. In particular, in relation to designing online materials, design of assessment must be incorporated from the initial stages of the design process just as when a teacher is planning a face-to-face lesson, the learning outcomes, activities and assessments need to be designed to be closely aligned [14]. Design decisions include the purposes of the assessment, consideration of whether the assessment is self, peer, teacher or automated process, practical and educational considerations regarding the mode of delivery and particular technologies to be used if appropriate, as well as what knowledge and skills are to be assessed.

\section{A framework for design considerations}

Designing assessments can be supported by a framework to encourage thinking and discussion in relation to specifying learning outcomes (LOs) and designing associating learning activities assessments. A revised version [3] of Bloom's taxonomy of educational objectives [23] provides a useful framework for considering learning outcomes and how to assess them. Bloom's taxonomy was originally developed to facilitate sharing of test items between university faculties. The revised version [3] takes account of advances in cognitive psychology and other developments since the original taxonomy was published. Whereas Bloom's original taxonomy is arranged as a one-dimensional hierarchy with a built-in expectation of progression between levels, the revised framework is two-dimensional. There is still an indication of a hierarchy but it is acknowledged that categories overlap and the constraint of the "cumulative hierarchy" has been removed [24]. The taxonomy is generally represented as a table (see Table 2)

The intention is that any learning outcome can be characterised in terms of both knowledge and cognitive processes and thus can be categorised into one of the cells in the table. Using the table to examine alignment between learning outcomes, instructional activities and assessments is a key aim of the development of the taxonomy [24]. 
Table 2. The Taxonomy Table [3]

\begin{tabular}{|l|l|l|l|l|l|l|}
\hline \multicolumn{9}{|c|}{ The Cognitive Process Dimension } \\
\hline $\begin{array}{l}\text { The } \\
\text { Knowledge di- } \\
\text { mension }\end{array}$ & Remember & Understand & Apply & Analyse & Evaluate & Create \\
\hline $\begin{array}{l}\text { Factual } \\
\text { knowledge }\end{array}$ & & & & & & \\
\hline $\begin{array}{l}\text { Conceptual } \\
\text { knowledge }\end{array}$ & & & & & & \\
\hline $\begin{array}{l}\text { Procedural } \\
\text { knowledge }\end{array}$ & & & & & & \\
\hline $\begin{array}{l}\text { Metacognitive } \\
\text { knowledge }\end{array}$ & & & & & & \\
\hline
\end{tabular}

Table 3. Proposed framework to support considerations for designing assessments

\begin{tabular}{|l|l|}
\hline Type of LO & \multicolumn{1}{c|}{ Examples of Appropriate Assessments } \\
\hline Remember & $\begin{array}{l}\text { Objective test items such as fill-in-the-blank, matching, labeling, or multi- } \\
\text { Recall } \\
\text { Recognize }\end{array}$ \\
terms, facts, and concepts
\end{tabular}


Based on theoretical, pedagogical and practical considerations outlined earlier in this article, Webb et al. [2] developed a framework to support considerations for designing assessments. The framework was based on the revised Bloom's taxonomy and also incorporated technical considerations, consideration of the purpose of the assessment: whether formative or summative, the assessor (peer, teacher, self, computer) and examples of appropriate assessment activities (see Table 3).

\section{$8 \quad$ Enabling practitioners to design assessments}

As explained above, considerations for designing assessments include:

- the type of learning outcomes that can be considered using the revised Bloom's Taxonomy

- who is to assess - whether peer, teacher, self, technology

- the purpose of assessment i.e. formative or summative

- technical considerations such as infrastructure requirements

- whether suitable computer-based tools are available and the particular advantages of each type of tool.

Thus, the range of possible approaches and their advantages and limitations exist in a complex decision space. While teachers, rather than IT developers, are best placed to understand assessment requirements and student needs, it is challenging for teachers to be aware of the range of possibilities as well as the consequences of their decisions about how to assess. Webb et al. [2] addressed this professional development challenge by designing a decision support tool which helped the user to create an assessment plan by asking a series of questions and highlighting the implications of their choices (see Figure 1).

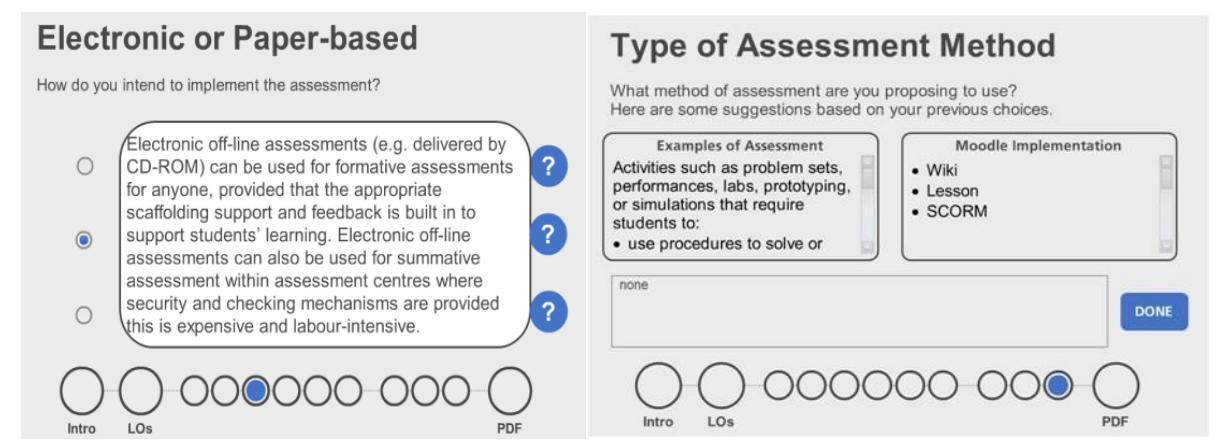

Fig. 1. - Screenshots of Assessment Decision Support Tool a) when the user is checking the implications of using "electronic off-line delivery" and b) suggestions for assessments and ways of implementing after a user has input their series of answers. 
The benefits of using a decision support tool for designing assessments are that such a tool can contain a set of rules about the relative advantages and limitations of various different approaches to assessment and the outcomes of using the tool, in the form of advice to the user, can be tailored in response to the user's needs as indicated by their answers to the questions. Nevertheless, because the assessment design is dependent on the large range of issues and factors discussed in this article, we recommend that such tools are used in professional development sessions where there are opportunities for discussion, negotiation and collaboration.

\section{References}

1. E-QUAL Enhancing Quality, A.a.G.o.U.E.i.I. 2017; Available from: http://www.projectequal.net/equal/index.php.

2. Webb, M., et al. Assessment for Blended Learning Scenarios: A Decision Support Tool. 2017. Cham: Springer International Publishing.

3. Anderson, L.W., D.R. Krathwohl, and B.S. Bloom, A taxonomy for learning, teaching, and assessing: a revision of Bloom's taxonomy of educational objectives. 2001: Longman.

4. Webb, M.E., D.C. Gibson, and A. Forkosh-Baruch, Challenges for information technology supporting educational assessment. Journal of Computer Assisted Learning, 2013. 29(5): p. 451-462.

5. Assessment Reform Group, A., Assessment for Learning: 10 Principles. 2002.

6. Zheng, Q., L. Chen, and D. Burgos, The International Comparison and Trend Analysis of the Development of MOOCs in Higher Education, in The Development of MOOCs in China. 2018, Springer Singapore: Singapore. p. 19.

7. Butler, R., Enhancing and undermining intrinsic motivation; the effects of task-involving and ego-involving evaluation on interest and performance. British Journal of Educational Psychology, 1988. 58: p. 1-14.

8. Giles, T., S. Gilbert, and L. McNeill, Do students want and need written feedback on summative assignments. Engaging students with the feedback process: A topic review activity. ergo: The Journal of the Education Research Group of Adelaide, 2013. 3(1): p. 15-21.

9. Douglas, T., et al., The feedback process: Perspectives of first and second year undergraduate students in the disciplines of education, health science and nursing. Journal of University Teaching \& Learning Practice, 2016. 13(1): p. 3.

10. Sadler, D.R., Beyond feedback: developing student capability in complex appraisal. Assessment \& Evaluation in Higher Education, 2010. 35(5): p. 535 -550 .

11. Black, P., et al., Assessment for learning: putting it into practice. 2003, Buckingham, UK: Open University.

12. Liu, N.-F. and D. Carless, Peer feedback: the learning element of peer assessment. Teaching in Higher Education, 2006. 11(3): p. 279-290. 
13. Webb, M.E., Beginning teacher education and collaborative formative eassessment. Assessment and Evaluation in Higher Education, 2010. 35(5): p. $597-618$.

14. Black, P., Formative assessment - an optimistic but incomplete vision. Assessment in Education: Principles, Policy \& Practice, 2015. 22(1): p. 161177.

15. Grau, V. and D. Whitebread, Self and social regulation of learning during collaborative activities in the classroom: The interplay of individual and group cognition. Learning and Instruction, 2012. 22(6): p. 401-412.

16. Li, H., et al., Peer assessment in the digital age: a meta-analysis comparing peer and teacher ratings. Assessment \& Evaluation in Higher Education, 2016. 41(2): p. 245-264.

17. Yeh, S.S., Understanding and addressing the achievement gap through individualized instruction and formative assessment. Assessment in Education: Principles, Policy \& Practice, 2010. 17(2): p. 169-182.

18. Clarke, J. and C. Dede, Assessment, technology, and change. Journal of Research in Teacher Education, 2010. 42(3): p. 309-328.

19. Gibson, D., C. Aldrich, and M. Prensky, Games and Simulations in Online Learning: Research and Development Frameworks. 2007, Information Science Publishing: Hershey, Pennsylvania.

20. Ridgway, J., S. McCusker, and D. Pead, Literature review of e-assessment. 2004: Futurelab.

21. Hatzipanagos, S. and S. Warburton, Feedback as dialogue: Exploring the links between formative assessment and social software in distance learning. Learning, Media and Technology, 2009. 34(1): p. 45-59.

22. Guri-Rosenblit, S., 'Distance education' and 'e-learning': Not the same thing. Higher Education, 2005. 49(4): p. 467-493.

23. Bloom, B.S., et al., Taxonomy of Educational Objectives, the classification of educational goals - Handbook I: Cognitive Domain. 1956, New York: McKay.

24. Anderson, L.W., Objectives, evaluation, and the improvement of education. Studies In Educational Evaluation, 2005. 31(2-3): p. 102-113. 